\title{
Phthiriasis palpebrarum in a Spanish infant
}

\author{
Carlos Izquierdo-Rodriguez $\oplus^{1,2}$, Maria Castro-Rebollo $\odot^{1,2}$, Yolanda Fernandez-Miguel ${ }^{1,2}$, \\ Paula Moreno-Martin ${ }^{1,2}$, Jesus Zarallo-Gallardo @ ${ }^{1,2}$ \\ 'Henares University Hospital, Spain \\ ${ }^{2}$ Facultad de Ciencias de la Salud, Universidad Francisco de Vitoria, Madrid, Spain
}

\begin{abstract}
BACKGROUND: Phthiriasis palpebrarum is an eyelid involvement secondary to an infestation of the eyelids by Phthirus pubis and has a low incidence.

CASE PRESENTATION: A 7-year-old male child presented in the emergency room at Henares Hospital in Madrid (Spain) with a history of repeated episodes of itchiness, blepharitis, warmth sensation, and moderate discomfort of 2 months duration in both eyes. Slit-lamp examination revealed lice and nits at the roots of the eyelashes. Many treatments have been described for the treatment of phthiriasis pubis. In this case, mechanical removal and treatment with vaseline ointment were performed.

CONCLUSION: A careful slit-lamp examination to identify the nits and lice in the eyelashes and careful removal is necessary for the best evolution.
\end{abstract}

KEY WORDS: phthiriasis palpebrarum; phthirus pubis; lice

Ophthalmol J 2021; Vol. 6, 69-71

\section{INTRODUCTION}

Phthiriasis palpebrarum is a rare eyelid disorder caused by Phthirus pubis. The records of pediculosis have history of more than 10,000 years. Lice eggs were found in the Judean Desert, located in the Nahal Herman Cave [1]. Louse eggs were discovered in the hair of bodies buried in the ruins of the Herculaneum.

Lice are blood-sucking insects, and they are specific parasites of human beings. They can be found in different parts of the body, such as pubic hair in its primary location. Other areas of the body with hair can also be the place of the crab lice nesting. Less frequently, the eyelashes may be affected [2]. Sexual contact is the main route of transmission of pubic lice in adults. However, in children, the spread is due to close contact, sleeping with infested parents in the same bed, or sexual abuse [3].
Acute blepharitis with an intense inflammatory reaction may be a manifestation of a Phthiriasis pubis infestation of the eyelashes. Hypersensitivity caused by louse can lead to secondary conjunctivitis. Clinical signs similar to allergic blepharoconjunctivitis could be found [4]. Thereby a careful slit-lamp examination is necessary to correctly evaluate cases of eyelid inflammation that do not evolve as expected and are resistant to usual treatment [5].

\section{CASE REPORT}

A 7-year-old male child was presented to the emergency room at Henares Hospital in Madrid (Spain) with a two-month history of itching and pain in the eyelids. Honey colored crusts secretions adhered to the eyelashes, and a sign of blepharitis with small skin lesions on the lid margins of both 


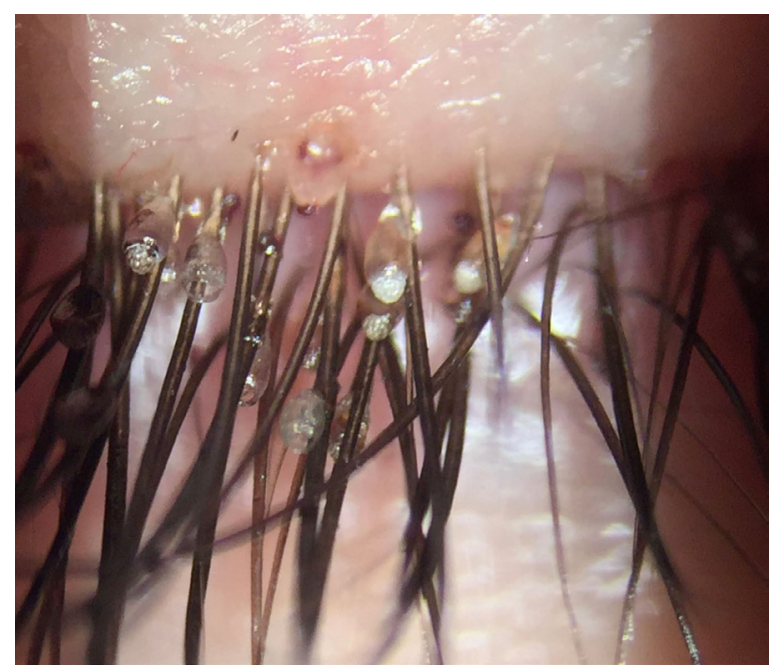

FIGURE 1. Phthiriasis palpebrarum. Nits attached to the eyelashes

eyes were observed. Careful examination by slit lamp revealed a few lice. What looked like characteristic blepharitis secretions secondary to Demodex turned out to be crab eggs at the roots of the eyelashes (Fig. 1). On examination, the patient's visual acuity was $6 / 6$ in both eyes. The conjunctiva of both eyes was normal, and no signs of conjunctivitis were found.

Lice and nits founded attached to the eyelashes were removed using fine forceps. The patient was advised to apply vaseline ointment three times daily over the lid margins. Oral ivermectin $4 \mathrm{mg}$ in a single dose was prescribed, repeated seven days later, along with permethrin $5 \%$ cream.

A week later, at the control examination, eggs and crabs and the lesions on the lid margin persisted in the left eye.

The patient's parents reffered that the boy's eyes continued to be infested with lice, and that ocular rubbing persisted.

A careful examination with a slit lamp allowed us to verify that what we believed to be secondary skin lesions to scratching were actually crabs that had managed to establish themselves subcutaneously in order to feed (Fig. 2). We maintained the treatment with ointment three times daily over the lid margins and removed the rest of the eggs that we observed.

Four weeks later, no more lice or nits were seen.

\section{DISCUSSION}

Lice are blood-sucking insects that can be found in the pubic region [6]. These lice are named Phthirus pubis or crabs. The parasite usu-

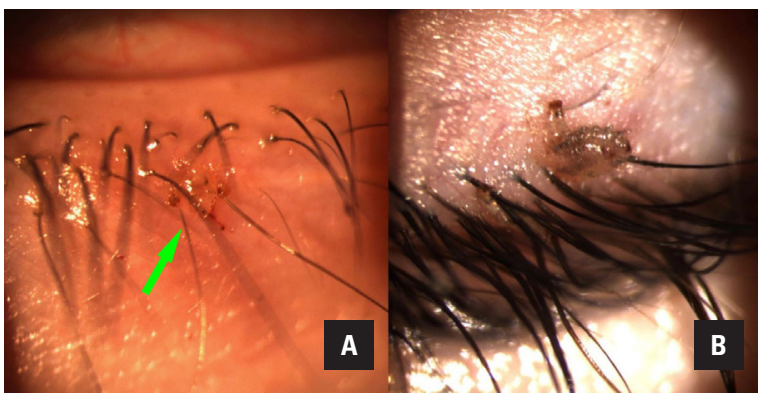

FIGURE 2. A. Pthirus pubis simulating scratching wound; B. Phthiriasis palpebrarum embedded in the eyelid skin and feeding on blood

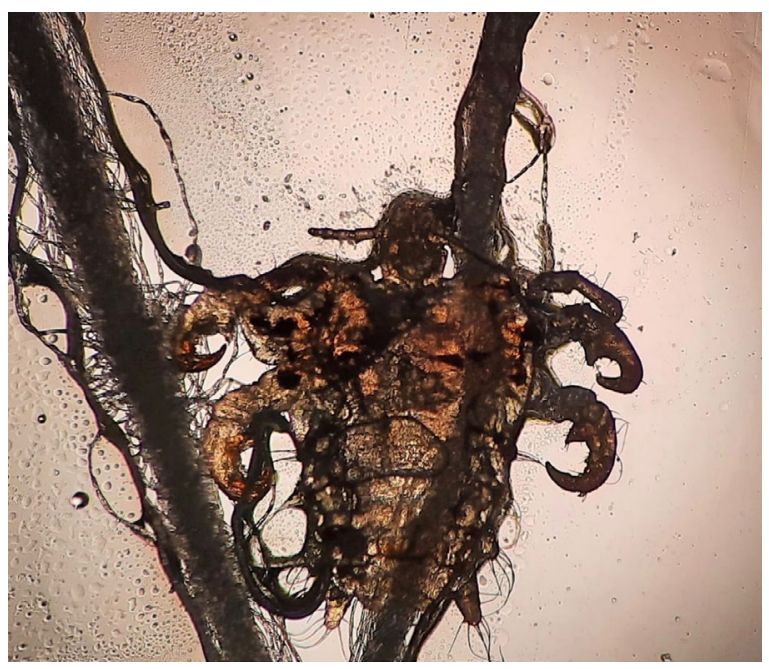

FIGURE 3. Microscopic view of crab louse Pthirus pubis.

The hooks with which they grip the hair follicles of the eyelashes are appreciated

ally reaches the eye through hands after contact with the infested genital area or by sexual contact. The crabs are $1-3 \mathrm{~mm}$ long and have three pairs of legs [4] (Fig. 3). The life cycle of the female is 1-3 months. The adult female lays 3-10 eggs/day. These eggs adhere to the hair at the skin-hair junction. Over their lifetime, each female may lay 50 to 300 eggs. The eggs are deposited at the base of the hair. These are translucent, ovoid, and capped, about $0,5 \mathrm{~mm}$ in size, and remain strongly adhered thanks to a cementing substance of chitin that surrounds the egg and hair. Eggs or nits hatch in about 6-10 days. These nymphs mature to adult form within ten days. Larvae and adults can not survive longer than one day without feeding. Mature adults live 3-6 weeks and then die within 1-3 days when far from their host. While feeding, crab louse grabs human hair with its second or third legs. The louse 


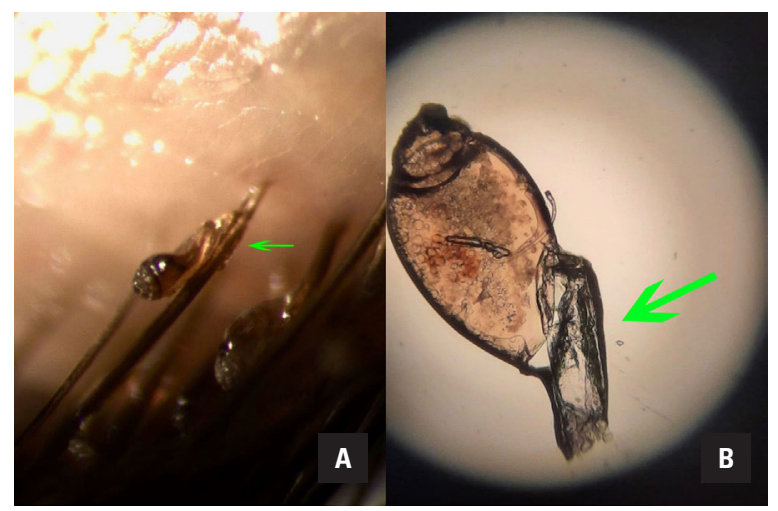

FIGURE 4. A. Microscopic view of the egg; B. The eggs are attached to the hair follicles through a chitin sheath that surrounds the egg

inserts its mouthparts into the host's skin and sucks blood intermittently for hours [3].

Different treatments have been reported in the literature: cryotherapy [7], argon laser photocoagulation [8], but they require patient's cooperation. In young children, sedation or general anesthesia may be necessary. Cogan and Grant [9] reported the use of anticholinesterase such as physostigmine ointment, but this treatment does not affect the nits and has many side effects. The use of Botulinum toxin $\mathrm{A}$ to treat phthiriasis palpebrarum was reported in a case report by Vaitheeeswaran et al. [10]. Botulinum toxin A is known to cause neuromuscular paralysis through action on nicotinic receptors, which are also present in parasites such as the Phthiriasis pubis. The authors applied a solution of 2.5 units $/ 0.1 \mathrm{~mL}$ uniformly to wet the lashes along the margins of the eyelid of 6-year-old patient. Other treatments include the use of fluorescein eye drops $20 \%$, lindane $1 \%$, physostigmine $0.25 \%$, petroleum gel, yellow mercuric oxide ointment $1 \%$ [11], malathion drops $1 \%$ or malathion shampoo $1 \%$, oral ivermectin and pilocarpine gel $4 \%$ [12]. There are a variety of available treatments, but the most used is manual parasite removal with forceps. Family members, sexual and close contacts should all be examined and treated appropriately, if necessary. Ngai suggested that the patient's and fam- ily's towels, bedding, and clothes should be washed at $\geq 50^{\circ} \mathrm{C}$ within three days of treatment and dried on the hot cycle for 5-10 min.

\section{CONCLUSION}

Phthirus pubis infestation of the eyelids is commonly misdiagnosed as blepharoconjunctivitis. A careful slit-lamp examination of the eyelid margins and eyelashes is necessary since there are crabs that can go unnoticed as they are hidden under the palpebral margin. Despite the availability of several topical and oral treatments, the direct removal with forceps of the lice and nits along with the vaseline ointment application and oral therapy is proven to be a safe and effective treatment.

\section{REFERENCES}

1. Zias J, Mumcuoglu KY. Pre-pottery neolithic B head lice from Nahal Hemar Cave. Atigot. 1991; 20: 167-68.

2. Turgut $B$, Kurt $\mathrm{J}$, Catak 0 , et al. Phthriasis palpebrarum mimicking lid eczema and blepharitis. J Ophthalmol. 2009; 2009: 803951, doi: 10.1155/2009/803951, indexed in Pubmed: 20339456.

3. Ryan MF. Phthiriasis palpebrarum infection: a concern for child abuse. J Emerg Med. 2014; 46(6): e159-e162, doi: 10.1016/j.jemermed.2013.11.090, indexed in Pubmed: 24556565.

4. Yi JW, Li Li, Luo DaW. Phthiriasis palpebrarum misdiagnosed as allergic blepharoconjunctivitis in a 6-year-old girl. Niger J Clin Pract. 2014; 17(4): 537-539, doi: 10.4103/1119-3077.134063, indexed in Pubmed: 24909484.

5. de Pinho Paes Barreto R, Biancardi AL, Salgueiro MJ. Chronic conjunctivitis related to phthiriasis palpebrarum. Int Ophthalmol. 2012; 32(5): 467-469, doi: 10.1007/s10792-012-9528-2, indexed in Pubmed: 22707338.

6. Maunder J. Lice and scabies. Dermatologic Clinics. 1998; 16(4): 843-845, doi: 10.1016/s0733-8635(05)70058-9.

7. Awan KJ. Cryotherapy in phthiriasis palpebrarum. Am J Ophthalmol. 1977; 83(6): 906-907, doi: 10.1016/0002-9394(77)90922-9, indexed in Pubmed: 868994.

8. Awan KJ. Argon laser phototherapy of phthiriasis palpebrarum. Ophthalmic Surg. 1986; 17(12): 813-814, indexed in Pubmed: 3822386.

9. Cogan DG, Grant WM. Treatment of pediculosis ciliaris with anticholinesterase agents; report of a case. Arch Ophthal. 1949; 41(5): 627, doi: 10.1001/archopht.1949.00900040643011, indexed in Pubmed: 18128051.

10. Vaitheeswaran K, Garg S, Kaur P. Botulinum toxin A in the treatment of pthiriasis palpebrarum. J AAPOS. 2014; 18(3): 290-291, doi: 10.1016/j.jaapos.2013.12.010, indexed in Pubmed: 24735800.

11. Ashkenazi I, Desatnik HR, Abraham FA. Yellow mercuric oxide: a treatment of choice for phthiriasis palpebrarum. $\mathrm{Br} \mathrm{J}$ Ophthalmol. 1991; 75(6): 356-358, doi: 10.1136/bjo.75.6.356, indexed in Pubmed: 2043580.

12. Burkhart CN, Burkhart CG. Oral ivermectin therapy for phthiriasis palpebrum. Arch Ophthalmol. 2000; 118(1): 134-135, indexed in Pubmed: 10636433. 